\title{
Effects of age, body weight, body condition and scrotal circumference on sperm abnormalities of bulls used for artificial insemination (AI) programme in Bangladesh
}

\author{
Md. Jalal Uddin Sarder* \\ Department of Animal Husbandry and Veterinary Science, University of Rajshahi, Rajshahi-6205, Bangladesh \\ *Email: jalalnusa@yahoo.com
}

\begin{abstract}
Impacts of age, body weight, body conditions, and scrotal circumference on sperm abnormalities of bulls used for artificial insemination (AI) in Bangladesh have been studied. During 1997-2002, 1390 ejaculates of semen from 71 bulls from Central Cattle Breeding Station and Dairy Farm, Savar, Dhaka, Rajshahi Dairy and Cattle Improvement Farm, Rajabarihat, and District Artificial Insemination Centre, Rajshahi, were collected and examined. Total head abnormalities, free loose head, mid-piece, tail abnormalities, proximal and distal cytoplamic droplets, total tail abnormalities and total sperm abnormalities were recorded. Age of the bulls had significant effect on sperm abnormalities $(\mathrm{P}<0.01)$ except for proximal cytoplasmic droplet. Similarly, body weight had significant effect $(\mathrm{P}<0.05)$ except for the total head abnormalities, while body conditions had no significant effect on mid-piece, total tail abnormalities and total sperm abnormalities except for the total head abnormalities. Scrotal circumference had significant effect $(\mathrm{P}<0.05)$ on all the sperm abnormalities. The present results demonstrate that the middle ( 8 to $<10 \mathrm{yrs})$ and older ( $>10 \mathrm{yrs}$ ) bulls having body weight of $<450$ $\mathrm{kg}$, very good body condition and 36 to $<38 \mathrm{~cm}$ scrotal circumference had the lowest sperm abnormalities. The need for semen examination for morphological abnormalities of spermatozoa in bulls to be used for AI programme is strongly implicated by this study.
\end{abstract}

Key words: Bull sperm abnormalities, age, body weight, body conditions, scrotal circumference, artificial insemination $(\mathrm{AI})$

\section{Introduction}

A common saying that 'the bull is half of the herd' is taught in animal husbandry, and the reason behind the statement is that the sire is one of the parents of all the calves in the herd while a dam is a parent of one calf per season. Semen is the secretion of male reproductive glands containing the male gametes (spermatozoa) produced in the testis (Hafez, 1993). Among the reproductive traits, quality semen plays a major role in determining the fertility and reproductive efficiency of any livestock production. The abnormal sperm heads and tails originate in the testis and epididymis, respectively (Blom, 1950). Low reproductive efficiency of cattle is a problem to both dairy and beef cattle breeders. Since fertility is determined from the results of mating between male and female, a part of low breeding efficiency is due to the bull (Haque, 1968). The incidence of spermatozoa with abnormal morphology in fertile bulls was found to be $0-18 \%$ (Saacke, 1970; Rao, 1971) whereas Zemjanis (1970) reported that these abnormalities could be as high as $30-40 \%$. Elliot (1978) recommended not tolerating more than $20 \%$ abnormalities of sperm head and/or mid-piece in routine artificial insemination (AI) practice. The information available on the semen characteristics of purebred and crossbred bulls is very meager (Rao \& Rao, 1979; Abraham et al., 1982). Abnormalities of the spermatozoa occur due to disorder of the semeniferous tubules, during ejaculation or in manipulation of the ejaculate including excessive agitation, over-heating to rapid cooling, mixture of water, urine or antiseptic in the semen (Hossain et al., 1990). In the process of evolving new types of crossbred cattle with different levels of exotic germplasm, the use of purebred and crossbred bulls in the breeding programme has become imminent. Spermatozoa with abnormal morphology are the most important factor that has direct bearing on fertility of bulls for successful AI programmes. Experiments reveal that the proportion of morphologically abnormal spermatozoa in the semen correlates negatively with fertility results (Shamsuddin et al., 1993), whereas morphologically abnormal spermatozoa are unable to fertilize the oocytes (Shamsuddin \& RodriguezMartinez, 1994). Crossbreeding of indigenous cows with exotic bulls has been accepted as an effective method for bringing about a quick genetic improvement of cows for increased milk production (Sultana, 1995). Recent studies have shown that $11 \%$ or more head, mid-piece or tail abnormalities and $18 \%$ or more total abnormalities of spermatozoa are associated with reduced fertility in bulls (Sarder, 2004). In this study impacts of age, body weight, body conditions and scrotal circumference on sperm abnormalities of bulls used in three AI centres in Bangladesh have been evaluated.

Materials and Methods

Experimental Bulls and parameters used: A total of 1390 ejaculates of semen collected from 71 bulls used for AI programmes in Bangladesh at Central Cattle Breeding Station and Dairy Farm, Savar, Dhaka, Rajshahi Dairy and Cattle Improvement Farm, 
Rajabarihat and District Artificial Insemination Centre, Rajshashi, during 1997-2002. A total of 714 ejaculates of semen for head abnormalities and 676 for tail abnormalities were used. Bulls were classified into 4-5 groups according to their age, body weight, body conditions and scrotal circumference (Table-1). Age of the bulls was determined from the birth register and by examining their teeth. The body weight of each bull was recorded in $\mathrm{kg}$ using large weighbridge or calculated according to the Shaeffer's formula (McNitt, 1983): $\mathrm{L} \times \mathrm{G}^{2} / 300 \times 2.2$ where $\mathrm{L}=$ body length in inch, and $\mathrm{G}=$ girth in inch. The body conditions of the bulls were scored into 1 to 4 scales (Nicholson \& Butterworth, 1986). Measurements of the scrotal circumference were made at the area of the largest diameter of the scrotum using a cloth tape as described by Ott (1991).

Feeding and management of bulls: Stall-feeding was practiced regularly and concentrate feeds were given twice (mornings and evenings) daily. Concentrate feeds include chickpea, wheat bran, oil cake, rice bran, urea, molasses and salt. The green grasses like Para, Napier, maize and oats and in the form of silage were also supplied on the basis of year round availability. The bulls were also fed a balanced ration of $50 \%$ mixed concentrate hay supplemented with vitamins and minerals. All bulls were tested for fertility

Semen samplings: Semen was collected from the bulls using a standard artificial vagina at an interval of 3 to 4 days. The bull calves were selected, brought up in the farm and trained for semen collection from 18 months of age. Records such as the dates of collection, dates of culling and dates of death were maintained. Semen was sampled immediately after collection at a frequency of once in a month for each bull.

Staining techniques: A thin smear of fresh semen was prepared on a grease-free slide for the study of morphological abnormalities of sperm head after passing through Williams' stain. (Williams, 1920). The stain was prepared as follows: Stock solution-I contained $10 \mathrm{~g}$ basic Fucshin and 95\% alcohol. Stock solution-II consisted of saturated bluish eosin in 95\% alcohol. Stock solution-III contained $10 \mathrm{ml}$ stock solution-I and $170 \mathrm{ml} \mathrm{5 \%}$ phenol. The final stain contained $25 \mathrm{ml}$ stock solution-II and $50 \mathrm{ml}$ stock solution-III. The stain was filtered before use. The smear was air-dried and fixed in flame. Such information as bull ID and date of semen collection were marked on slide with the help of a permanent marker pen. Then the smear was treated with absolute alcohol for 3-4 min and washed with $0.5 \%$ chloramine for 1-2 min until it appeared fairly clear. Then it was washed in distilled water followed by rinsing in $95 \%$ alcohol and finally stained with Carbol-Fucshin eosin for 8-10 min. After staining, the slides were washed in running tap water, dried off and examined under light microscope at $1000 \times$.

Examination of sperm abnormalities: The normal sperm heads were free from any detectable abnormalities. Any head abnormalities in spermatozoa were detected and categorized according to Williams' (1920) classification. At least 500 spermatozoa from separate individual smears were examined for head abnormalities and microphotographs were taken. The morphology of sperm mid-piece and tail was studied after fixing with buffered Formol-saline at ambient temperature. The saline was prepared according to the method described by Hancock (1957) that consisted of $34.4 \mathrm{mmol}$ di-sodium hydrogen phosphate $\left(\mathrm{Na}_{2} \mathrm{HPO}_{4}\right.$. $2 \mathrm{H}_{2} \mathrm{O}$ ), $18.7 \mathrm{mmol}$ potassium di-hydrogen phosphate $\left(\mathrm{KH}_{2} \mathrm{PO}_{4}\right), 92.6 \mathrm{mmol}$ sodium chloride $(\mathrm{NaCl}), 1.54$ mmol formaldehyde and distilled water to constitute $1000 \mathrm{ml}$.

One ml Formol-saline was taken in a sample glass tube and a small drop of fresh semen $(10 \mu l)$ was mixed, shaken and marked with the information like bull ID, breed and date of semen collection. The sample was preserved in a refrigerator at $4{ }^{\circ} \mathrm{C}$ for later examination. The abnormalities of the smeared spermatozoa were observed under a phase contrast microscope at $1000 \times$ (Olympus CH-2, Japan), and some of them were selected for microphotographs. At least 200 spermatozoa from individual smears were examined for tail abnormalities.

Statistical analysis: Data were subjected to analysis of variance (ANOVA) and Duncan's Multiple Range Test (DMRT) using the computer programme SPSS (version 10.1). Interpretations were derived from the data categorized into total sperm abnormalities owing to age, body weight, body conditions and scrotal circumference of the bulls under study (Steel \& Torrie, 1980).

Table 1. Bulls classified according to the parameters used.

\begin{tabular}{|c|c|c|c|c|c|}
\hline \multirow[t]{2}{*}{ Parameters } & \multicolumn{5}{|c|}{ Groups } \\
\hline & I & II & III & IV & $\mathbf{V}$ \\
\hline Age (yrs) & $<4$ & 4 to $<6$ & 6 to $<8$ & 8 to $<10$ & $>10$ \\
\hline Body weight $(\mathrm{kg})$ & $<450$ & 450 to $<550$ & 550 to $<650$ & $>650$ & - \\
\hline Body conditions & Average & Good & Very good & Excellent & - \\
\hline Scrotal circumference $(\mathrm{cm})$ & $<34$ & 34 to $<36$ & 36 to $<38$ & $>38$ & - \\
\hline
\end{tabular}




\section{Results and Discussion}

Head abnormalities, and mid-piece and tail abnormalities owing to the age, body weight, body conditions and scrotal circumference of the bulls under study have been presented in Plate 1 and Plate 2, respectively. Hence, the effects of different parameters on the incidence of sperm abnormalities are detailed in the following paragraphs. (Sharma et al., 1991).

Age: Significant proportions of head and tail abnormalities were observed in bulls belonging to different age groups $\left(\mathrm{F}_{4,492}=5.591 ; \mathrm{P}<0.01\right.$; Fig. 1). The semen of bulls $<4$ yrs of old contained the highest percentage of total head abnormalities of spermatozoa followed by $6-<8$ yrs, $4-<6$ yrs, 10 yrs and $8-<10$ yrs age groups. There was no significant variation in the percentage of mid-piece and proximal cytoplasmic droplets abnormalities between the bulls under study. The highest mid-piece abnormalities of spermatozoa was found in $8-<10 \mathrm{yrs}$ and the lowest in $>10 \mathrm{yrs}$ age
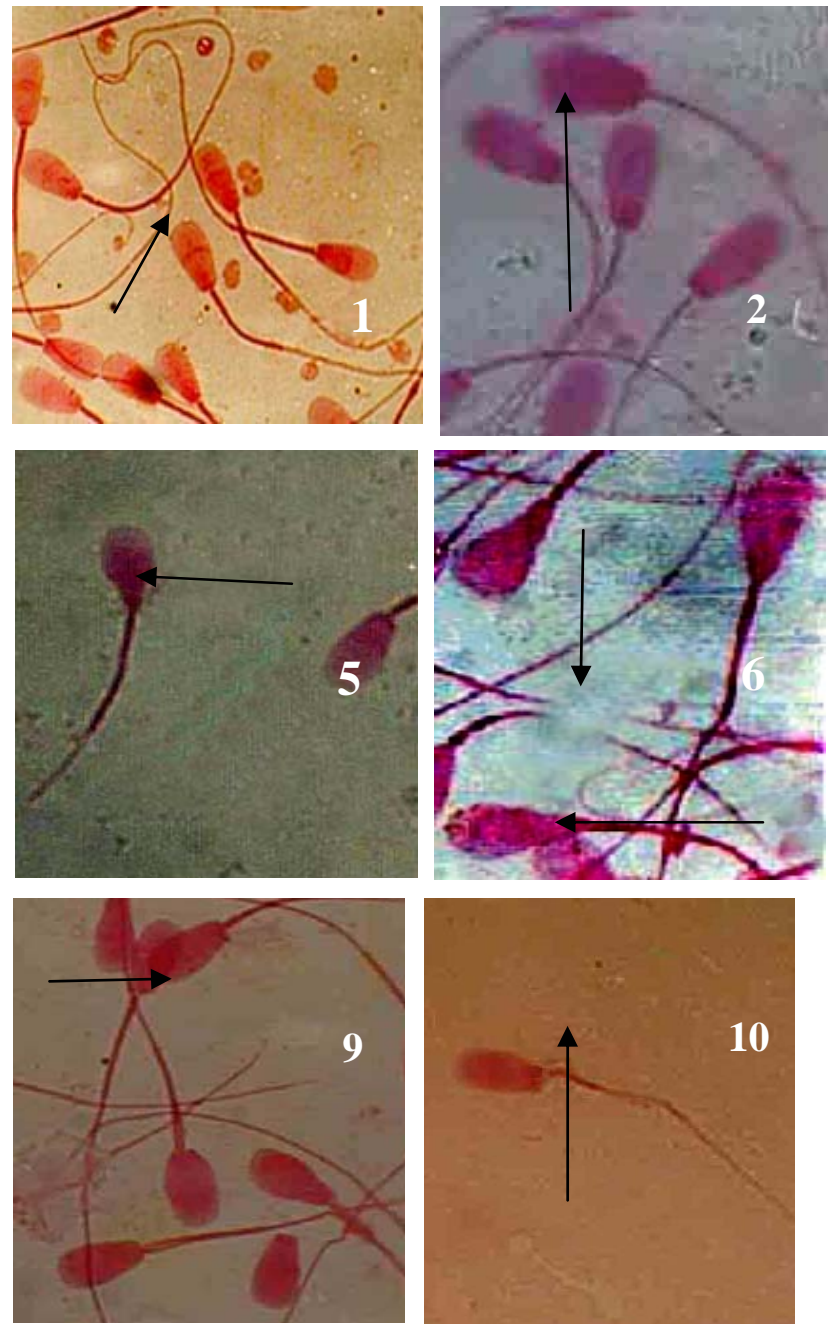

groups. The highest percentage of total tail abnormalities was recorded in $6-<8$ yrs followed by 8 $<10 \mathrm{yrs},<4 \mathrm{yrs},>10 \mathrm{yrs}$ and $4-<6$ yrs groups. The highest percentage of total sperm abnormalities $(17.58 \%)$ was recorded in bulls of $<4$ yrs and the lowest $(15.84 \%)$ in $>10$ yrs. Previous study showed that the age of bulls had highly significant effect on all the semen characteristics where the percentage of abnormal spermatozoa increased with growing age (Tomar et al., 1985). Moreover, collection frequency, pre-collection sexual stimulation, feeding regime and climatic conditions can also influence the sperm abnormalities (Al-Hakim et al., 1986). The present study indicated that age of the bulls has much bearing on the proportion of sperm abnormalities. The differences of sperm abnormalities, however, could also be due to variations in the breed, age and the secretory activities of the sex glands (Leon et al., 1991.
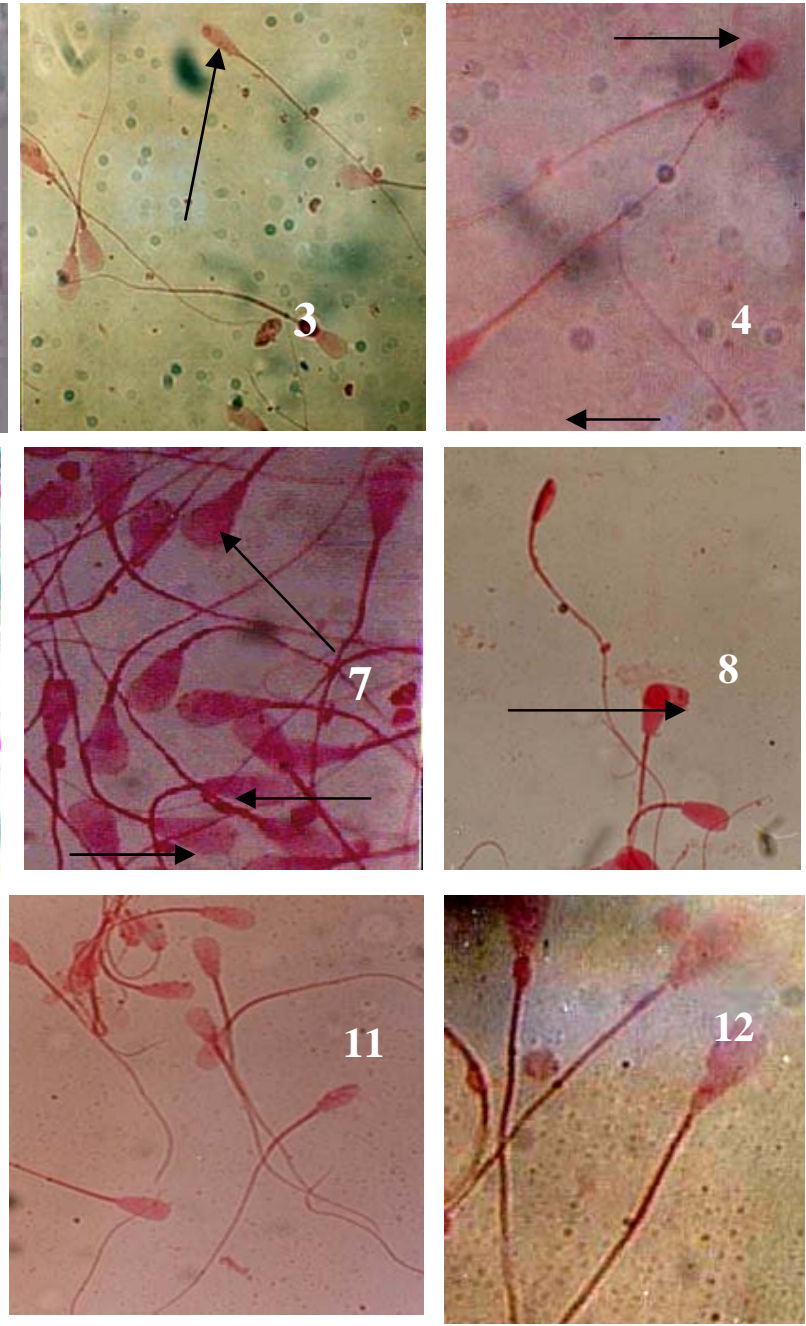

Plate 1. Microphotographs of normal and abnormal head morphology of bull spermatozoa (Williams' stain 1000x). (1) Normal (2) Big (3) Narrow (4) Round (5) Pear-shaped (6) Narrow at base (7) Constricted in lower portion (8) Undeveloped (9) Broad (10) Abaxial (11) Little and (12) Abnormal contour 

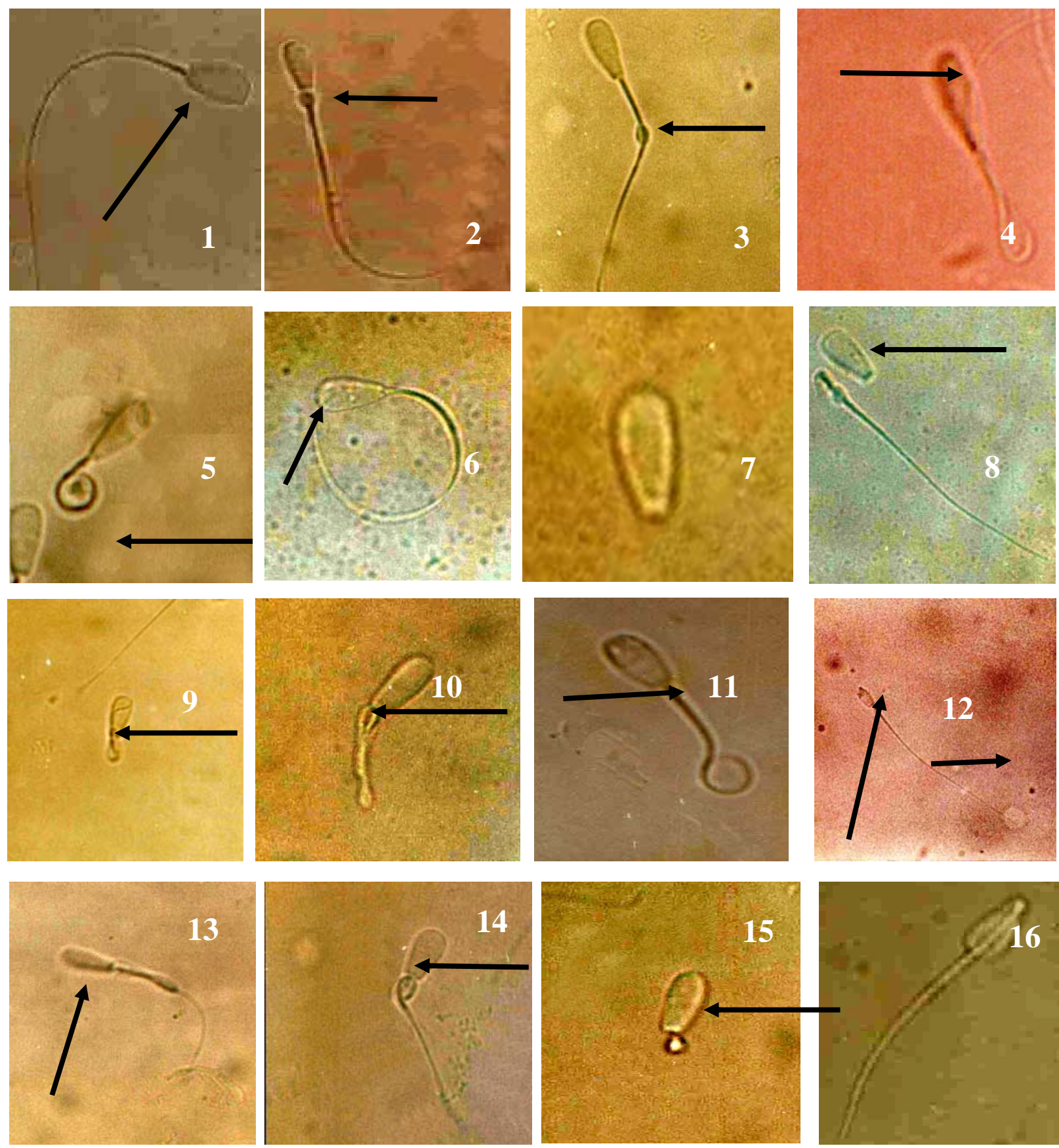

Plate 2. Microphotographs of normal and abnormal bull spermatozoa with respect to the mid-piece and tail (Phase contrast optics, 1000x). (1) Normal (2) Proximal cytoplasmic droplet (3) Distal cytoplasmic droplet (4) Simple bent (5) Coiled (6) Coil around the head (7) Free loose (8) Head detached from mid-piece (9) Mid-piece and tail defect (10) Double folded (11) Coiled in lower part (12) Abnormal acrosome (13) Folded (14) Mid-piece defect (15) Tailless mid-piece and (16) Tail broken at the neck

Body weight: The results on the sperm abnormalities due to body weight of the experimental bulls are presented in Fig. 2. The body weight was found to have a significant effect on the mid-piece and tail sperm abnormalities $\left(\mathrm{F}_{3,493}=2.643 ; \mathrm{P}<0.05\right)$. The highest percentage of mid-piece abnormalities was observed in $450-<550 \mathrm{~kg}$ and the lowest in $<450 \mathrm{~kg}$ weight groups. The highest proportion of total sperm abnormalities $(17.07 \%)$ was recorded in bulls of $>650 \mathrm{~kg}$ body weight followed by $450-<550 \mathrm{~kg}, 550-<650 \mathrm{~kg}$ and $<450 \mathrm{~kg}$ (abnormalities of $16.44 \%, 16.34 \%$ and $15.81 \%$, respectively). Previous investigators (Saacke, 1970; Rao, 1971) observed $0-18 \%$ spermatozoa with abnormal morphology in fertile bulls whereas Zemjanis (1970) reported $30-40 \%$ total spermatozoon abnormalities in the semen of fertile bulls. Variations in the body weight and body size could give rise to differences in sperm abnormalities in bulls (Leon et al., 
1991; Sharma et al., 1991). Sarder et al. (2001) demonstrated a significant effect of body weight on semen characteristics. These findings are in good agreement with that of the present study.

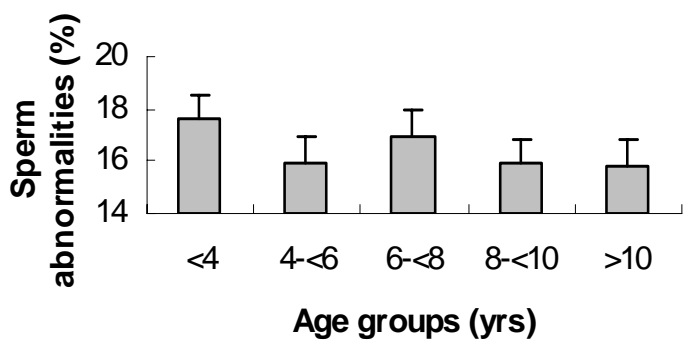

Fig. 1. Effect of age on total sperm abnormalities (mean $\pm \mathrm{SD}$ ) in bulls used for AI.

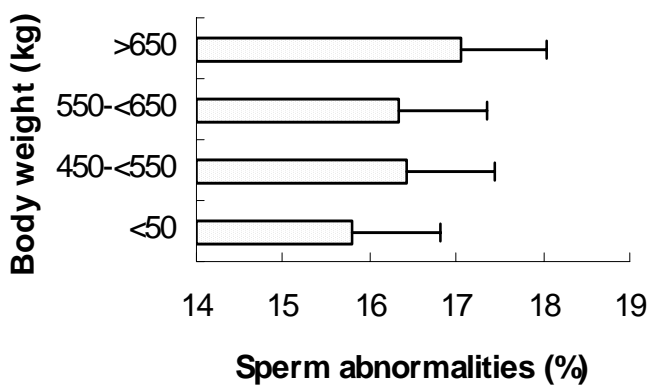

Fig. 2. Sperm abnormalities (mean $\pm \mathrm{SD}$ ) in different body weight groups of bulls used for AI.

Body conditions: Fig. 3. shows a non-significant association of sperm abnormalities with the body conditions of the breeding bulls (Table 2). Notably the highest head abnormalities were recorded in bulls with excellent body condition, followed by average, very good and good body conditions. As has been reported earlier (Hossain et al., 1990), abnormalities of the spermatozoa could occur due to disorder of the semeniferous tubules or germina epithelium, which is directly or indirectly related to the body conditions of the bulls, the present results appear to fall within the normal variation range.

Scrotal circumference: The effect of scrotal circumference on the total abnormalities of spermatozoa in bulls is presented in Fig. 4. The over-all effect was statistically significant $\left(\mathrm{F}_{3,493}=3.293\right.$;
$\mathrm{P}<0.05)$, where the highest head abnormalities $(6.04 \%)$ were recorded in $<34 \mathrm{~cm}$ and the lowest (5.29\%) in $>38$ $\mathrm{cm}$ scrotal circumference groups. The variations in the mid-piece abnormalities were non-significant between the groups. The highest proportion of mid-piece abnormalities was observed in $36-<38 \mathrm{~cm}$ and the lowest in $<34 \mathrm{~cm}$ groups. The variations in the tail abnormalities were also found to be significant. The highest percentage of tail abnormalities was observed in $>38 \mathrm{~cm}(6.64 \%)$ and the lowest in $<34 \mathrm{~cm}(5.96 \%)$ groups. The highest percentage of total sperm abnormalities $(17.00 \%)$ was recorded in $>38 \mathrm{~cm}$ groups followed by $<34 \mathrm{~cm}(16.76 \%), 34-<36 \mathrm{~cm}(16.39 \%)$ and $36-<38 \mathrm{~cm} \quad(15.73 \%)$ groups. The sperm abnormalities occur during spermatogenesis either during spermatocytogenesis from spermatogonia to spermatids or during spermatogenesis from spermatids to spermatozoa (Blom, 1950). Previous reports suggests that young bulls with small scrotal circumference might have significantly lower fertility than the bulls with larger scrotum, and bulls with small testicles have semen with a higher percentage of sperm defects (Achnelt et al., 1964). The present differences in sperm abnormalities between four groups of bulls, however, may not only be attributable to the variation of their scrotal circumference, but also to the differences in breed, age, body weight and body conditions coupled with the secretory activity of the sex glands (Leon et al., 1991; Sharma et al., 1991).

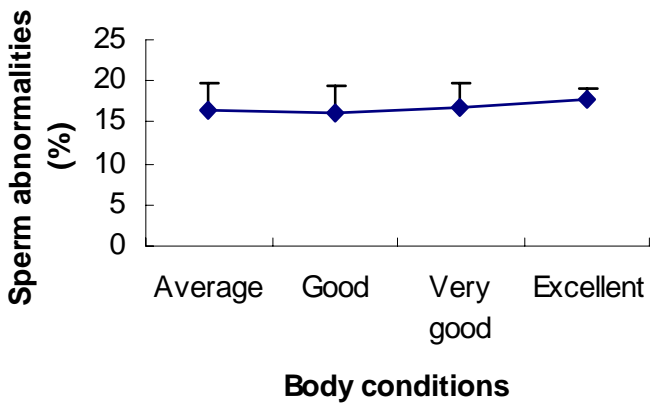

Fig. 3. Effect of body conditions on total sperm abnormalities (mean $\pm \mathrm{SD})$ in AI bulls.

Table 2 Analysis of variance table showing the total sperm abnormalities due to the age, body weight, body conditions and scrotal circumference of 71 bulls used for AI programme.

\begin{tabular}{c|c|c|c|c|c}
\hline Parameters & Sources of variation & Df & Sum of squares & Mean of squares & F-values \\
\hline \multirow{2}{*}{ Age } & Between groups & 4 & 230.945 & 4.533 & $5.591^{* *}$ \\
\cline { 2 - 6 } & Within groups & 492 & 5080.978 & 10.327 & \\
\hline \multirow{2}{*}{ Body weight } & Between groups & 3 & 84.088 & 28.029 & $2.643^{*}$ \\
\cline { 2 - 7 } & Within groups & 493 & 5227.835 & 10.604 & \\
\hline \multirow{2}{*}{ Body conditions } & Between groups & 3 & 45.683 & 15.228 & $1.426^{\mathrm{ns}}$ \\
\cline { 2 - 7 } & Within groups & 493 & 5266.682 & 10.682 & $3.293^{*}$ \\
\hline \multirow{2}{*}{ Scrotal circumference } & Between groups & 3 & 44.994 & 14.998 & 10.546 \\
\cline { 2 - 7 } & Within groups & 493 & 5199.038 & & \\
\hline
\end{tabular}

$\mathrm{Df}=$ degrees of freedom; $*=\mathrm{P}<0.05 ; * *=\mathrm{P}<0.01$. 


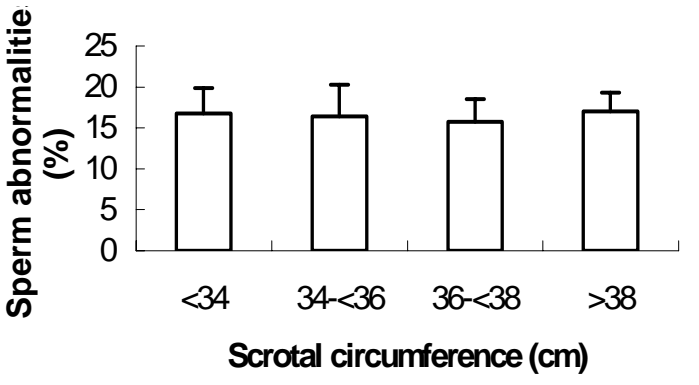

Fig. 4. Effect of scrotal circumference on total sperm abnormalities (mean $\pm \mathrm{SD}$ ) in AI bulls.

The present results suggest that the bulls of 8 to $>10 \mathrm{yrs},<450 \mathrm{~kg}$ body weight, having very good body condition and 36 to $<38 \mathrm{~cm}$ scrotal circumference ensure the lowest percentage of sperm abnormalities. These findings are of immense importance for the selection of breeding bulls to be used for the AI programme in different farms in the country.

Acknowledgements: For providing necessary facilities I am thankful to Mr. Abdur Razzaque Mia, former Director General, Directorate of Livestock Services, Dhaka and Prof. O. I. Joarder, Department of Genetic Engineering and Biotechnology, University of Rajshahi. I am also grateful to Prof. M. Saiful Islam, Department of Zoology, RU, for his critical reviewing of the manuscript and useful suggestions.

\section{References}

Abraham, M., Josepth, P.J. \& Jose, T.K. 1982. Semen characteristics of purebred and crossbred bulls. Indian Vet. J. 59: 364-367.

Achnelt, E., Hahn, J. \& Jaova, C.M. 1964. Clinical scrotal findings and sperm and sperm morphology as fertility indicator in AI bulls. $5^{\text {th }}$ Int. Congr. Anim. Reprod. Tremto. 7: 470-475.

Al-Hakim, M.K., Ali, S.B.A. \& Singh, B.P. 1986. Studies on semen characteristics of Karadi bulls. Anim. Breed. Abstr. 54: 155.

Blom, E. 1950. On the Evaluation of Bull Semen. Ph.D Thesis. C. Mortensen, Copenhagen, Denmark.

Elliott, F.I. 1978. Significance of semen quality. In: Physiology of Reproduction and Artificial Insemination of Cattle (Salisbury GW, Van Demark NL and Lodge JR Eds), pp. 428-441. W.H. Freeman and Company, San Francisco, USA.

Hafez, E.S.E. 1993. Reproduction of Farm Animals (5th edn). Philadelphia, Lea \& Febiger. USA

Hancock, J.L. 1957. The morphology of boar spermatozoa. J. Res. Microbiol. Soc. 76: 84-97.

Haque, M. 1968. Repeatability of semen characteristics of yearling beef bulls. Anim. Sci. J. East Pakistan. 1-2: 34-38.

Hossain M.F., Alam, M.G.S., Ahmed J.U., Rahman, M.M. \& Rahman, A. 1990. Bacteriological examination of semen as an aid to sexual health control in bulls. Bangl. J. Microbiol. 7: 85-88.
Leon, H., Porras, A.A. \& Galina, C.S. 1991. Effect of collection method on semen characteristics of zebu and European type cattle in the tropics. Theriogenology. 6: 349-355.

McNitt, J.L. 1983. Livestock Husbandry Technique ( $1^{\text {st }}$ edn). ELBS, London.

Nicholson, M.J. \& Butterworth, M.H. 1986. A Guide to Condition Scoring of Zebu Cattle. International Livestock Center for Africa Ababa, Ethiopia. 29 pp.

Ott, R.S. 1991. Breeding Soundness Examination of Bulls. Department of Veterinary Medicine. Urbana, Illinois, USA.

Rao, A.R. 1971. Changes in the morphology of sperm during their passage through genital in bull abnormal and impaired spermatogenesis. Unpubl. Ph. D. Thesis. Stockholm.

Rao, T.L.N. \& Rao, A.R. 1979. Fertility and its relationship with semen characteristics in crossbred bulls. Indian Vet. J. 56: 33-36.

Saacke, R.G. 1970. Morphology of the sperm and its relationship to fertility. Proc. $3^{\text {rd }}$.Tech. Conf. A.I. and Reprod. Feb. 19-21. USA.

Sarder, M.J.U. 2004. Morphological sperm abnormalities of different breeds of bull and its impact on conception rate of cows in AI programme. Bangl. J. Vet. Med. 2: 129135.

Sarder, M.J.U., Jorder, O.I. \& Ali, M.S. 2001. Studies on phenotypic and genotypic variation in the semen traits of seven AI bulls. Bangladesh j. genet. biotechnol. 2: 3542.

Shamsuddin, M. \& Rodriguez-Martinez, H. 1994. A simple, non- traumatic culture method for the selection of spermatozoa for in vitro fertilization in the bovine. Anim. Reprod. Sci. 36: 61-75.

Shamsuddin, M., Rodriguez-Martinez, H. \& Larsson, B. 1993. Fertilizing capacity of bovine spermatozoa selected after swim up in hyaluronic acid containing medium. Reprod. Fertil. Develop. 5: 307-315.

Sharma, M.L., Mohan, G.\& Sahni, K.L. 1991. Characteristics and cryopreservation of semen of Holstein-Friesian bulls under tropics. Indian J. Anim. Sci. 61: 977-979.

Steel, R.G.D. \& Torrie, J.H. 1980. Principles and Procedures of Statistics. A Biometrics Approach. McGraw-Hill, New York, USA.

Sultana, R. 1995. Quantitative analysis of reproductive performance of purebred and their crosses in the Savar Dairy Farm. Unpubl. M. Sc. Thesis, Department of Animal Breeding and Genetics. BAU, Mymensingh.

Tomar, N.S., Sharma, K.C. \& Shukla, S.N. 1985. Semen production in relation to the age of Holstein Friesian $\times$ Harina bulls. Indian Vet. J. 62: 499-501.

Williams, W.W. 1920. Technique of collecting semen for laboratory examination with a review of several diseased bulls. Cornell Vet. 10: 87-94.

Zemjanis, R. 1970. Collection and evaluation of semen. In: Diagnostic and Therapeutic Techniques in Animal Reproduction ( $2^{\text {nd }}$ edn). pp. 139-156. Wilkins Co.Baltimore, USA.

Manuscript received on 24.07.2008, accepted on 23.092008 